المجلد: (الأول)

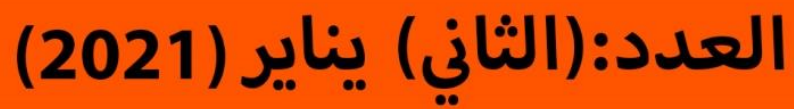

\title{
International Journal of Humanities and
} Social Sciences Research and Studies

\section{المجلة الدولية لبحوث ودراسات العلوم الإنسانية والاجتماعية (IJHS)}

مجلة علمية دورية محكمة تصدرهـا أكاديـميـه رواد التميـز للتعليم والتدريب والاستشارات والتنمية البشرية

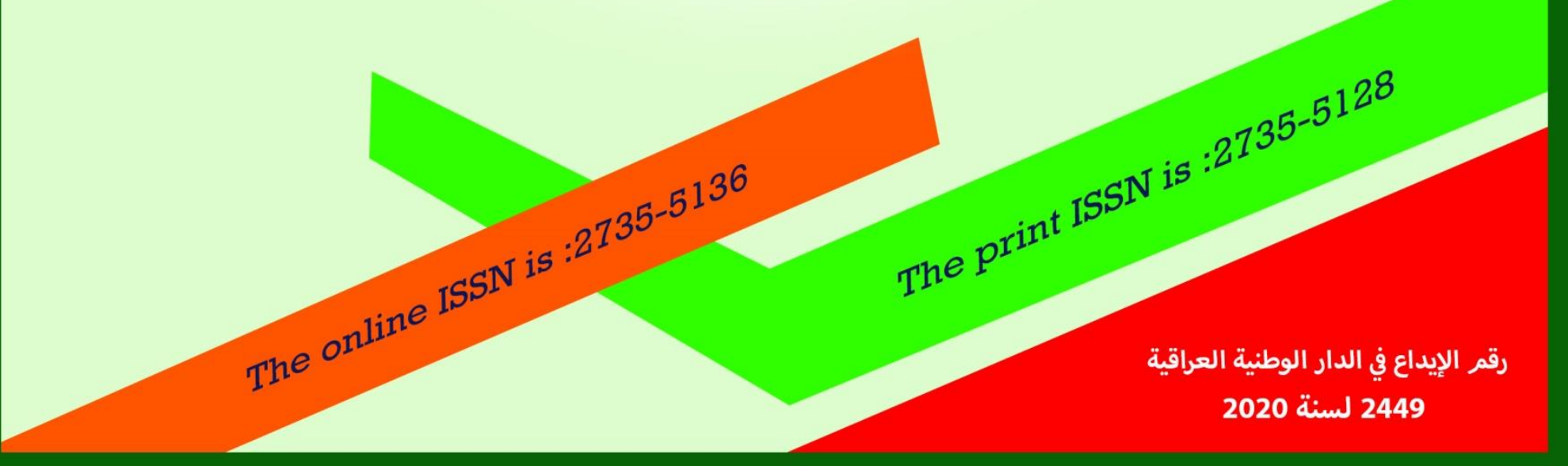


المجلة الدولية لبحوث ودراسات العلوم الإنسانية والاجتماعية (ISSH) المجلد:(الأول) العدد:(الثاني) يناير 2021 د. خليل كحم الخطيب _ د.محم ضيف الله الثماري ، (واقع التعليم الإلكتروني بالجامعات اليمنية).

\section{واقع التعليم الإكتروني بالجامعات اليمنية \\ ومقترحات تطويره في ظل انتشار وباء كورونا.}

د.تحمح ضيف الله الثماري.

د. خليل حما الخطيب.

جامعة صنعاء - اليمن.

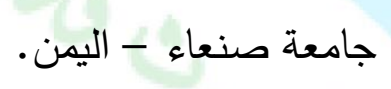

ملخص البحث:

يهدف البحث إلى تثخيص واقع التعليم الإكتروني بالجامعات اليمنية وتقديم الرؤى ومقترحات تطويره في ظل انتشار وباء كورونا، وأعتمد البحث على المنهج الوصفي التحليلي، باستخدام اسلوب تحليل المضمون للأدبيات والتقارير ذات العلاقة، وتمثلت مشكلة البحث في الإجابة عن السؤالين التاليين:

1. ما الجهود المبذولة لوزارة التعليم العالي والبحث العلمي باليمن تجاه التعليم الآكتروني؟ 2. ما واقع نظام التعليم الإكتروني بالجامعات اليمنية؟ وما أبرز التحديات التي تواجهه؟ خلص البحث إلى جملة من النتائج، أبرزها: - قطعت وزارة التعليم العالي والبحث العلمي باليمن خطوات جيدة من الناحية القانونية، وأصدرت الضوابط والقواعد اللازمة للتعليم عن بعد والتعليم الففتوح عام 2007. ومنحت تراخيص لبعض الجامعات، خلال 2000- 2012، وفي 2013 أوقفت الوزارة هذا النظام

\section{0}

\section{International Journal of Humanities} and Social Sciences Research and Studies (IJHS) The print ISSN is: $2735-5128$ The online ISSN is: $2735-5136$ It is issued by the Excellence Pioneers Academy 
المجلة الدولية لبحوث ودراسات العلوم الإنسانية والاجتماعية (IJSH) المجلد:(الأول) العدد:(الثاني) يناير 2021 د. خليل تحمه الخطيب ـ د.تمحم ضيف الله الثماري ؛ (واقع التعليم الإلكتروني بالجامعات اليمنية).

- - مؤقتا، بهدف المراجعة والتقييم، وفي 2016 تم إيقافه بشكل قاطع، وأصدر مجلس الاعتماد - الأكاديمي وضمان الجودة معايير التعليم عن بعد عام 2017.

- وبصورة عامة؛ يتسم واقع التعليم الإلكتروني بالجامعات اليمنية بالضعف والقصور ، مع وجود عدد من التحديات، أبرزها: ضعف القدرة المؤسية للجامعات، وخاصة في الجانب التكنولوجي، وغياب الثقافة العلمية الإكترونية، ونقص التمويل، وضعف الرقابة والمتابعة والثفافية، بالإضافة إلى أثار الحرب والحصار على اليمن، مما يعني عدم جاهزية الجامعات اليمنية حاليا للتعليم الاككتروني.

- أدى انتثار جائحة كورونا كوفيد 19 إلى تعليق الدراسة في اليمن، واضطراب العملية التعليمية، وشعور قادة التعليم العالي والجامعات والمجتمع بالقلق، مما جعل الوزارة تدرك أهمية التعليم الإكتروني في التعليم الجامعي، وضرورة تطويره لمواجهة المخاطر والأوبئة. - قدم البحث عددا من التوصيات ومقترحات التطوير في مجال التعليم الإلكتروني باليمن.

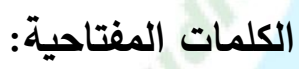

$$
\text { التعليم العالي - التعليم الإككتروني - وباء كورونا - الجامعات اليمنية.| }
$$

\section{Actuality of E-learning in Yemeni Universities and Suggestions to Promote It under the Outbreak of Coronavirus Pandemic}

Dr. Khalil Mohammed Al-Khateeb Sana'a University
Mohammed Dayfallah Al_Shamary.

Sana'a University

\section{Abstract}

The present study aimed at diagnosing actuality of e-learning in Yemeni universities and proposing perspectives and suggestions to promote it under the

International Journal of Humanities and Social Sciences Research and Studies (IJHS) The print ISSN is: $2735-5128$ The online ISSN is: $2735-5136$ It is issued by the Excellence Pioneers Academy 
المجلة الدولية لبحوث ودراسات العلوم الإنسانية والاجتماعية (ISSH) المجلد:(الأول) العدد:(الثاني) يناير 2021 د. خليل كحم الخطيب ـ د.نحم ضيف الله الثماري 6 (واقع التعليم الإلكتروني بالجامعات اليمنية).

outbreak of Coronavirus pandemic. The study followed the descriptive and analytic approach by analyzing the content of literature and relevant reports. The problem of the study could be represented by the following two questions:

1. What are the efforts of the Ministry of Higher Education and Scientific Research towards e-learning?

2. What is the actuality of e-learning in Yemeni universities? And what are the most prominent challenges which confront it?

The study revealed the following results:

- In 2007, the Ministry of Higher Education and Scientific Studies made progressive steps in the legal aspect and issued necessary laws and regulations for e-learning and distance learning. It granted licenses for some universities during the period 2000 - 2012. In 2013, the Ministry suspended this system temporarily for review and evaluation. In 2016, this system was stopped conclusively, and in 2017, the Council of Academic Accreditation and Quality Assurance issued standards of distance learning.

- In general, e-learning in Yemeni universities is featured as incapable and insufficient, besides the availability of many challenges most prominent of which are: weakness of the institutional capacity of universities, especially in the technological aspect; absence of the electronic and scientific culture; lack of funding; weakness of surveillance, monitoring, and transparency; in addition to the consequences of civil war and blockade on Yemen. This means that Yemeni universities are not currently ready for e-learning.

- The outbreak of the Coronavirus pandemic, COVID-19, led to: suspension of study in Yemen; malformation of the educational process and; leaders of the Ministry of Higher Education, universities, and community feel worried. This has made the Ministry realized the importance of e-learning in university education, and the necessity to promote it in order to confront risks and epidemics.

- The research presented some recommendations and suggestions to promote e-learning in Yemen.

Keywords: Higher Education, E-learning, Coronavirus epidemic, and Yemeni universities.

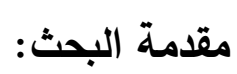

تتعدد أنماط التعليم؛ خصوصا في التعليم العالي، حسب إمكانات المؤسسات الجامعية

102

ومؤهلات وقدرات كوادرها، ومن هذه الأنماط الثائعة نمط التعليم التقليدي الذي يركز إلى حد ما 
المجلة الدولية لبحوث ودراسات العلوم الإنسانية والاجتماعية (ISSH) المجلد:(الأول) العدد:(الثاني) يناير 2021 د. خليل تحمه الخطيب ـ د.محم ضيف الله الثماري 6، (واقع التعليم الإلكتروني بالجامعات اليمنية).

على الددرس كمصدر أساسي للمعلومات، وتتم بالاعتماد على وسائل تعليمية تقليدية كالكتاب الورقي والقلم والسبورة والمحاضرة كوسيلة تعليمية وحيدة.

وظهرت أنماط تعليمية أخرى، حيث انتشر التعليم الجامعي المفتوح في انحاء متعددة من العالم؛ لاعم أنظمة التعليم التقليدي فيها؛ ولتحسين وتتمية مواردها البشرية، ففي المملكة المتحدة البريطانية ارتبطت نشأة التعليم المفتوح والتعليم من بعد بالتعليم العالي والتدريب المهني، واعتمد قطاع التجارة على تعليم وتدريب الموظفين من بعد، وفي الولايات المتحدة الأمريكية لعب التعليم الجامعي المفتوح من بعد لسنوات عديدة دورا رئيسا في قدرة وكفاءة المؤسسات الامريكية، كما وفر مرونة لدقابلة الحاجات المتغيرة للمجمع ومؤسساته في فترة زمنية قصيرة، وكانت بريطانيا من أولى الدول التي أنثأت جامعة مفتوحة عام 1969، ثم تلتها عدة دول من بينها اسبانيا 1972، والمانيا الغربية 1974، وكندا 1975، والصين 1978، وهولندا 1982، واليابان 1982. (الفقي، 2010، 627)، نقلا عن (جمال الدين، 1995، 78).

كما أن زيادة الطلب الاجتماعي على التعليم مع عجز النظام التعليمي عن توفير فرص تعليمية للجميع، ورغبة كل اسرة في أن يلتحق ابناؤها بالتعليم حتى وإن عجزت إمكاناتهم وقدراتهم على تحقيق تلك الفرص، أدى إلى أهمية الوقوف على صيخ تربوية جديدة تحاول أن تسد العجز في فرص التعليم النظامية الموجودة. (فراج، 2014، 38).

وشهد العقد الأخير من القرن العشرين وبدايات القرن الحادي والعشرين، تقدما هائلا في مجال تكنولوجيا المعلومات، وحولت الوسائل التكنولوجية الحديثة العالم إلى قرية كونية صغيرة. وانعكس and Social Sciences Research and Studies (IJHS) The print ISSN is: $2735-5128$ The online ISSN is: $2735-5136$ It is issued by the Excellence Pioneers Academy 
المجلة الدولية لبحوث ودراسات العلوم الإنسانية والاجتماعية (ISSH) المجلد:(الأول) العدد:(الثاني) يناير 2021 د. خليل كحم الخطيب ـ د.نحم ضيف الله الثماري ؛ (واقع التعليم الإلكتروني بالجامعات اليمنية).

هذا التطور في مجالات عديدة، إلا أن المجال الذي استفاد منه بصورة كبيرة هو التعليم، الذي يعتمد على هذه التقنيات وأصبح يسمى بالتعليم الإكتروني (وزارة التخطيط، 2014، 32- 33). وعلى إثر جائحة كورونا، فإنه "من المتوقع ان يعيد العالم - بما فيه العالم العربي - التنكير في ترتيب أولوياته من منظومة ترفيه الإنسان من رياضة وتمثيل وغناء وفنادق وقصور إلى منظومة بناء عقل الإنسان والحفاظ على صحته وبقائه من معلمين وأساتذة جامعات وباحثين وأطباء وممرضين ومدارس وجامعات ومستشفيات ومراكز أبحاث ومراكز صحية" (حيدر، 2020). وعلى كل دولة أن تتشئ لها نظاما تعليميا إلكترونيا بديلاً تتم إتاحته في الأوقات العادية كأداة مساعدة في العملية التعليمية، وكأداة أساسية في أوقات الأزمات والكوارث المناخية أو الطبيعية أو المرضية، التي يصعب معها الاعتماد على التعليم النظامي التقليدي.. وعدم ترك الأمور لكل فرد يستخدم الأدوات التي يريدها بشكل عشوائي، (الدهثان، 2020، 7 - 8).

وفي الجمهورية اليمنية، تأسس التعليم الجامعي عام 1970، وهو عام ميلاد جامعتي صنعاء وعدن، كأول جامعتين في اليمن، وظهر التعليم العالي الخاص عام 1992، بإنشاء الكلية الوطنية للعلوم والتكنولوجيا، والتي تطورت لاحقا لتصبح جامعة العلوم والتكنولوجيا، واليوم وبعد مضي خمسون عاما على انطلاقة التعليم العالي، فقد وصل عدد الجامعات، إلى (63) جامعة وكلية، منها: (16) حكومية، و(47) أهلية، يوجد في صنعاء وحدها ما يعادل (47\%) من مجموع المؤسسات الجامعية اليمنية.(الخطيب، 2020، 4). وعلى الرغم من التطورات الكبيرة التي شهدها التعليم الجامعي في اليمن، إلا أن قدرته الاستيعابية لا تزال غير كافية، ولم تتمكن

\section{4}

\section{International Journal of Humanities} and Social Sciences Research and Studies (IJHS) The print ISSN is: $2735-5128$ The online ISSN is: $2735-5136$ It is issued by the Excellence Pioneers Academy 
المجلة الدولية لبحوث ودراسات العلوم الإنسانية والاجتماعية (IJSH) المجلد:(الأول) العدد:(الثاني) يناير 2021

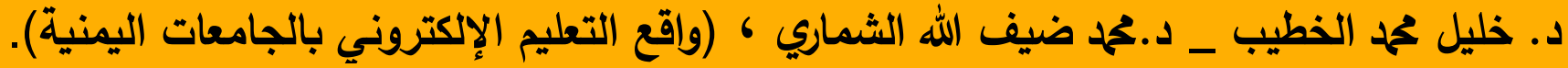

الجامعات الحكومية والخاصة في اليمن من استيعاب متخرجي الثانوية العامة عام 2014 إلا بنسبة (53\%). (الجمهورية اليمنية، 2015، 67).

كما لا تزال معظم الجامعات اليمنية تعتمد في التدريس على الأساليب التقليدية، المتمثلة في الالقاء من قبل المحاضر ، والتلقي السلبي من قبل الطلبة، وكذلك الاعتماد على المذكرات التي تكون عادة غير ملائمة في محتواها، ولا تواكب الجديد في موضوعها، وعلى الرغم من قلة الكتب والمراجع المتوفرة للطلاب، إلى جانب عدم التناسب بين عدد الطلبة وأعضاء هيئة التدريس، إلا أن ذلك لا يعد مبررا كافيا للاستمرار في استخدام هذه الأساليب التدريسية العتيقة، لأنها عاجزة عن مواكبة التطورات والمتطلبات اللازمة لتأهيل الطلبة في القرن الواحد والعشرين، الذي يقتضي اكتسابهم مهارات التفكير، ومهارات التعلم الذاتي المستمر • (وزارة التخطيط، .$(26-14 ، 2014$

وبدورها الجامعات اليمنية؛ تحاول تطوير أنظمتها التعليمية، والتغلب على اثار كورونا، من خلال انظمة التعليم الحديثة، كالتعليم الالكتروني، والتعليم عن بعد، ولكن تظل هناك تحديات كبيرة أمامها، تتلخص في غياب الموازنة العامة لوزارة التعليم العالي، وانقطاع المرتبات، وضعف البنية التحتية في الجوانب التتنية، وقلة الخبرات، وعدم وجود تدريب واعداد مسبق على التعامل مع الادوات التكنولوجية في التعليم الجامعي، وضعف خدمة الانترنت، وعدم تغطيتها لمختلف المحافظات، وخاصة في الارياف، والمناطق النائية، وانقطاع الكهرباء، بالإضافة إلى شيوع الامية التكنولوجية، ونقص الثقافة العلمية التتنية لاى الكثير من الهيئة التدريسية، وصعوبة تعامل الطلبة مع نمط تعليمي جديد، لم يعهدوه في مرحلة التعليم العام. (عبد الرزاق، 2020).

\section{International Journal of Humanities} and Social Sciences Research and Studies (IJHS) The print ISSN is: $2735-5128$ The online ISSN is: $2735-5136$ It is issued by the Excellence Pioneers Academy 
المجلة الدولية لبحوث ودراسات العلوم الإنسانية والاجتماعية (IJSH) المجلد:(الأول) العدد:(الثاني) يناير 2021 د. خليل تحمه الخطيب ـ د.بحمـ ضيف الله الثماري ؛ (واقع التعليم الإلكتروني بالجامعات اليمنية).

وقد بدأ اهتمام الباحثين اليمنيين بدراسة الجوانب المتصلة بالتعليم الاككتروني، والادارة الالكترونية، مطلع العشرينيات من القرن الحالي، فهناك الكثير من الدراسات الدحلية، والتي تطرقت لهذا الموضوع، ومنها دراسة (الجرادي، 2005)، والتي قدمت رؤية مستقبلية لإنثاء جامعة مفتوحة في الجمهورية اليمنية، ودراسة (باحشوان، 2007)، كدراسة استشرافية عن مستقبل التعليم عن بعد في جامعة حضرموت للعلوم والتكنولوجيا، وقدمت دراسة (مطهر، 2007)، جملة من الضوابط العامة للتعليم المفتوح والتعليم عن بعد. وجاءت دراسة (الرميمة، 2009)، لتشخيص واقع التعليم الجامعي عن بعد، واستشراف افاقه المستقبلية في الجمهورية اليمنية: جامعه العلوم والتكنولوجيا نموذجاً.

وتطرقت دراسة (الحيفي، 2009)، إلى تحديد معوقات استخدام أعضاء هيئة التدريس في

كليتي العلوم والتربية، بجامعة صنعاء للتتنيات التعليمية الرقمية، أما دراسة (قعشوش، 2011)، فتطرقت لواقع التعليم عن بعد في الجامعات والمعاهد العليا اليمنية، ومدى تطبيقه في تدريس مادة الرياضيات، وجاءت دراسة (المطري، 2011)، كدراسة تقويميه للتعليم الإكتروني في الجامعات اليمنية، في ضوء الاتجاهات العالمية المعاصرة، وهدفت دراسة (صالح، 2012)، إلى كثف واقع استخدام التعليم الإكتروني في كلية التربية والألسن بجامعة عمران.

كما تطرقت بعض الدراسات المحلية للجانب الاداري، باستخدام الادارة الالكترونية، ومنها دراسة (ابو غانم، 2013)، والتي قدمت تصور مقترح لتطبيق الادارة الاكترونية في كليات التربية بالجامعات الحكومية باليمن، أما دراسة (الدعيس، 2014)، فقدمت برنامج تدريبي مقترح

\section{6}

International Journal of Humanities and Social Sciences Research and Studies (IJHS) The print ISSN is: $2735-5128$ The online ISSN is: $2735-5136$ It is issued by the Excellence Pioneers Academy 
المجلة الدولية لبحوث ودراسات العلوم الإنسانية والاجتماعية (IJSH) المجلد:(الأول) العدد:(الثاني) يناير 2021 د. خليل كحم الخطيب ـ د.نحم ضيف الله الثماري 6 (واقع التعليم الإلكتروني بالجامعات اليمنية).

لتطوير المهارات الإدارية لاى القيادات الأكاديمية بجامعة تعز في ضوء متطلبات الإدارة الالكترونية، إلا أن الدراسات المحلية، عن تأثير وباء كورونا على قطاع التعليم العالي باليمن، وتقييم أنظمة التعليم الحالية، لا تزال نادرة، مما يستوجب تسليط الضوء على هذا الموضوع.

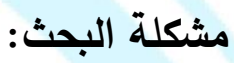

تسعى وزارة التعليم العالي والبحث العلمي في اليمن، إلى تحديث منظومة التعليم العالي باستمرار، ولو أنها تتسم بالبطء، وتواجه عددا من التحديات بين الحين والاخر ، مما يعني أن مسالة توظيف التكنولوجيا والتقنيات الحديثة في الجوانب الادارية والاكاديمية لدى الجامعات اليمنية، تظل التحدي الأكبر أمام الجهات المعنية، وعلى الرغم من ذلك، فقد اعتمدت الوزارة نظام التعليم عن بعد، ضمن أنظمتها التعليمية، ووضعت له الضوابط والقواعد العامة، وتم افتتاح بعض المراكز للتعليم الإكتروني في بعض الجامعات، إلا أن هذا النظام لم يكتب له الاستمرارية، فهو محاط بالعديد من العقبات، ولم تكتمل التجربة بعد، كما أضاف وباء كورونا تحديات جديدة لقطاع التعليم العالي برمته، مما يتطلب اعادة النظر ، وتقويم التجربة اليمنية، في مجال التعليم الالكتروني، ومن هنا تولدت مشكلة البحث الحالي، وتتمثل في السؤلين التاليين: 1. ما الجهود المبذولة لوزارة التعليم العالي والبحث العلمي باليمن تجاه التعليم الاكتروني؟ 2. ما واقع نظام التعليم الإككتروني بالجامعات اليمنية؟ وما أبرز التحديات التي تواجهه؟ 
المجلة الدولية لبحوث ودراسات العلوم الإنسانية والاجتماعية (IJSH) المجلد:(الأول) العدد:(الثاني) يناير 2021 د. خليل محما الخطيب ـ د.نحما ضيف الله الثماري 6 (واقع التعليم الإكتروني بالجامعات اليمنية).

$$
\text { تتمثل أهمية البحث في الاتي: }
$$

1- تسليط الضوء على جهود وزارة التعليم العالي في مجال التعليم الإكتروني باليمن.

$$
\text { 2- تسليط الضوء على واقع التعليم الإلكتروني بالجامعات اليمنية. }
$$

3- تقديم جملة من الرؤى والتوصيات والمقترحات لصناع القرار، والمسؤولون عن السياسة

التعليمية، وقادة التعليم العالي، قد تسهم في تطوير التعليم الإلكتروني لمواجهة الاوبئة.

$$
\text { أهداف البحث: }
$$

1. التعرف إلى جهود وزارة التعليم العالي والبحث العلمي باليمن تجاه التعليم الالكتروني.

2. تشخيص واقع التعليم الإكتروني بالجامعات اليمنية. وكشف المعوقات التي تواجهه.

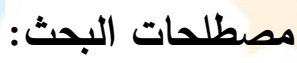

$$
\text { - التعليم الاكتروني: }
$$

يعرف التعليم الالكتروني، بأنه: "التعليم الميسر والمدعوم باستخدام تقنيات الاتصال والمعلومات، والذي يشمل أنشطة عديدة من التعلم المدعوم إلى التعلم المتنوع (مزيج من التعليم التقليدي والتعلم باستخدام التقنيات المتعددة)، إلى التعلم الكامل عبر الثبكة، ويتضمن ذلك استخدام الأقراص، مؤتمرات الفيديو، والتعلم التفاعلي عبر الشبكة، والبريد الاكتروني، وعبر الأقمار الصناعية، وغيره.(مطهر، 2007، 4). وتعرفه منظمة إديوكز الأمريكية، بأنه: "التعليم

\section{8}

\section{International Journal of Humanities} and Social Sciences Research and Studies (IJHS) The print ISSN is: $2735-5128$ The online ISSN is: $2735-5136$ It is issued by the Excellence Pioneers Academy 
المجلة الدولية لبحوث ودراسات العلوم الإنسانية والاجتماعية (ISSH) المجلد:(الأول) العدد:(الثاني) يناير 2021 د. خليل تحمه الخطيب ـ د.بحمد ضيف الله الثماري ؛ (واقع التعليم الإلكتروني بالجامعات اليمنية).

الذي يشمل مكونا على الانترنت، يساعد على التشارك، ويتح للمتعلمين الوصول إلى محتوى معرفي يتجاوز قاعة الدرس".(حيدر، 2015، 77).

ويعرف التعليم الإككتروني اجرائيا لأغراض البحث الحالي، بمجوعة العمليات المرتبطة بنقل وتوصيل مختلف أنواع المعرفة والعلوم إلى الدارسين في الجامعات اليمنية بإستخدام شبكة الانترنت، وتقنية المعلومات، والمستحدثات التكنولوجية.

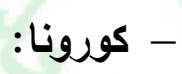

يمثل فيروس كورونا عائلة قائمة بذاتها من عوائل الفيروسات، وهو ذات فصائل متعددة منها فصيلة سارس، وفصيلة ميرسن وفصيلة كورونا الجديد 19 - covid، ترتبط هذه الفصائل بوشائج قربى كما ان بينها اختلافات في التركيب الجيني، ويعد 19 - covid، الفصيل السابع الككتثف حتى الان من هذه العائلة. وهو فيروس سريع الانتشار، يصيب الجهاز التنفسي واذا لم يكتثف ويعالج مبكرا قد يصل إلى مرحلة الالتهاب الرئوي. اكتثفت اول حالة لمصاب به في مدينة يوهان Wuhan بالصين في ديسمبر 2019. (السباعي، 2020، 10 - 12)

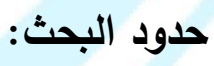

اقتصر البحث على تحليل واقع التعليم الإكتروني في الجامعات اليمنية ومتطلبات تطويره في

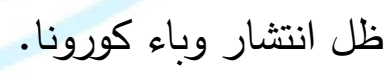


المجلة الدولية لبحوث ودراسات العلوم الإنسانية والاجتماعية (IJSH) المجلد:(الأول) العدد:(الثاني) يناير 2021 د. خليل كحم الخطيب ـ د. دحمد ضيف الله الثماري 6 (واقع التعليم الإكتروني بالجامعات اليمنية).

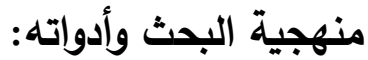

اعتمد البحث على المنهج الوصفي التحليلي، واسلوب تحليل المضمون، كأداة لجمع البيانات والمعلومات، من خلال الادبيات والتقارير ذات الصلة، المنشورة والموثقة، وتحليلها وتفسير نتائجها، واستخلاص ابرز الرؤى والتوصيات بثأن موضوع البحث. عرض نتائج البحث ومناقشتها:

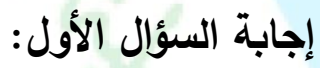

إجابة السؤال الأول، ونصه: ما الجهود المبذولة لوزارة التعليم العالي والبحث العلمي باليمن تجاه التعليم الالكتروني؟ وللإجابة على السؤال، تم استقراء الأدبيات السابقة، وتم استخلاص الاتي: نظرا لأهمية التخطيط الاستراتيجي، والتحديث المستمر، فقد أطلقت وزارة التعليم العالي والبحث العلمي مشروع تطوير التعليم العالي بتمويل أجنبي، وأصدرت في اطاره ما يسمى بالاستراتيجية الوطنية للتعليم العالي في الجمهورية اليمنية، وخطة العمل المستقبلية: 20062010، كأول خطة استراتيجية وطنية، واشارت إلى "أن أنماط التعليم الحديثة، كالتعليم الالكتروني، والتعليم عن بعد، هي من الفرص المتاحة للوزارة، ولمؤسسات التعليم العالي باليمن، في حال تم الاهتمام بهذا النوع من التعليم". (الجمهورية الينية، 2006). 
المجلة الدولية لبحوث ودراسات العلوم الإنسانية والاجتماعية (IJSH) المجلد:(الأول) العدد:(الثاني) يناير 2021 د. خليل تحما الخطيب ـ د.محمد ضيف الله الشماري 6 (واقع التعليم الإكتروني بالجامعات اليمنية).

ويعد نظام التعليم الإكتروني أحد الأنظمة التعليمية المعتمدة لدى وزارة التعليم العالي والبحث العلمي باليمن، إلى جانب اربعة أنظمة اخرى، يمكن ايجازها مع ذكر نظم القبول في الجامعات الحكومية والأهلية، كما ورد في (وزارة التعليم العالي، 2014، 24- 25)، كالاتي: - - أولا: أنظمة التعليم العالي المعتمدة باليمن.

1- نظام الفصول الدراسية: هذا النظام معمول به في معظم كليات الجامعات، وفيه تكون السنة الدراسية مكونة من فصلين دراسيين، كل فصل دراسي مكون من 16 أسبوعاً دراسياً، بما فيها فترة الاختبارات.

2- نظام السنة الدراسية: هذا النظام معمول به في بعض كليات الجامعات مثل كلية الشريعة

$$
\text { والقانون وكلية الطب البشري. }
$$

3- نظام الساعات المعتمدة: هذا النظام معمول به في بعض الجامعات الحكومية والأهلية. 4- نظام التعليم عن بعد والتعليم المفتوح.

5- نظام التجسير :( في الجامعات الأهلية فقط).

- - ثانيا: نظم القبول في الجامعات الحكومية والأهلية.

يوجد في اليمن خمسة نظم معتمدة للقبول والالتحاق بالجامعات، يمكن حصرها كالآتي:

\section{1}

International Journal of Humanities and Social Sciences Research and Studies (IJHS) The print ISSN is: $2735-5128$ The online ISSN is: $2735-5136$ It is issued by the Excellence Pioneers Academy 
المجلة الدولية لبحوث ودراسات العلوم الإنسانية والاجتماعية (IJSH) المجلد:(الأول) العدد:(الثاني) يناير 2021 د. خليل عحمل الخطيب ـ د.محمد ضيف الله الثماري ؛ (واقع التعليم الإلكتروني بالجامعات اليمنية).

$$
1
$$

2-ويتم به قبول الطلاب اليمنيين في الجامعات الحكومية بدون رسوم دراسية، وفي الجامعات والكليات الأهلية يتم قبول الطلاب برسوم دراسية وفقاً لما تحدده كل جامعة، وبحسب النسب

$$
\begin{aligned}
& \text { والطاقة الاستيعابية المقرة من المجلس الأعلى للتعليم العالي. } \\
& \text { 3- النظام الموازي( المسائي): }
\end{aligned}
$$

يقبل بموجب هذا النظام الطلاب الذين تقل معدلاتهم عن النسب المحددة في شروط القبول بالنظام العام، ويسمح لهم بالدراسة في الفترة المسائية بالرسوم الدحددة، على ألا يقل معدل الطلاب المقبولين عن 5\% من معدل القبول بالنظام العام، وبحيث لا يتجاوز عدد المقبولين به 25\%من إجمالي عدد الطلاب المقبولين بالنظام العام، وعلى مستوى كل كلية وتخصص في

$$
\text { الجامعات الحكومية. }
$$

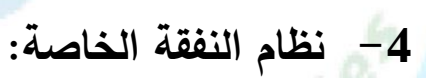

يقبل به الطلاب الذين لم يتمكنوا من النجاح في المنافسة بالنظام العام، أو الذين تقل معدلاتهم في الثانوية العامة بنسبة لا تتجاوز 5\% عن معدل الذين تم قبولهم بالنظام العام، ويتم قبولهم للدراسة في الفترة الصباحية برسوم دراسية تتفاوت بحسب نوع التخصص المطلوب الالتحاق به، وبحيث لا يتجاوز عدد المقبولين به 25\% من إجمالي عدد المقبولين بالنظام العام

$$
\text { على مستوى كل كلية وتخصص في الجامعات الحكومية. }
$$

\section{2}

\section{International Journal of Humanities} and Social Sciences Research and Studies (IJHS) The print ISSN is: $2735-5128$ The online ISSN is: $2735-5136$ It is issued by the Excellence Pioneers Academy 
المجلة الدولية لبحوث ودراسات العلوم الإنسانية والاجتماعية (IJSH) المجلد:(الأول) العدد:(الثاني) يناير 2021 د. خليل تحمه الخطيب ـ د.تحمد ضيف الله الثماري ؛ (واقع التعليم الإلكتروني بالجامعات اليمنية).

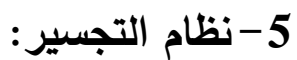

يُقصد به الانتقال من درجة الدبلوم إلى درجة البكالوريوس، ويهدف إلى الربط بين مراحل التعليم العالي المختلفة، ويكون هذا النظام خاصاً بالطلاب الحاصلين على مؤهلات دبلوم نظام السنتين أو دبلوم الثلاث سنوات، والراغبين في مواصلة دراستهم لنيل درجة" البكالوريوس"، وفقاً لضوابط القبول المحددة من قبل وزارة التعليم العالي والبحث والعلمي والمجلس الطبي، ويقتصر التحاق الطالب/ الطالبة بنظام التجسير في الجامعات والكليات الأهلية فقط بعد اجتياز امتحان الكفاءة الوزاري.

\section{6 - 6ظام التعليم عن بعد والتعليم المفتوح:}

يعُد التعليم عن بعد والتعليم المفتوح أحد الأنظمة التعليمية التي تعتمدها وزارة التعليم العالي والبحث العلمي بالجمهورية اليمنية، وفقاً للضوابط التي حددها القرار الوزاري رقم 170 لسنة 2007 م، ويقتصر هذا النظام على التخصصات الإنسانية فقط، ويُمنع في التخصصات التطبيقية التي لا يُسمح بها من قبل الوزارة.

وحرصت الوزارة على نشر ثقافة التعليم الآكتروني، استتادا إلى توجيهات الحكومة بشأن

إنشاء مراكز التعليم عن بعد، لمواكبة التطور التكنولوجي وشيوع التعليم الاكتروني، في معظم جامعات العالم. واقامت بعض الفعاليات، ومنها ورشة التعليم الإكتروني عن بعد في رحاب جامعة صنعاء في اغسطس 2006م، تم - من خلالاها - استعراض عدد من التجارب والخبرات العربية والعالمية، كان منها تجارب كل من: جامعة القدس المفتوحة، والجامعة العربية and Social Sciences Research and Studies (IJHS) 
المجلة الدولية لبحوث ودراسات العلوم الإنسانية والاجتماعية (IJSH) المجلد:(الأول) العدد:(الثاني) يناير 2021 د. خليل تحمه الخطيب ـ د.يحم ضيف الله الثماري ؛ (واقع التعليم الإلكتروني بالجامعات اليمنية).

المفتوحة، والتجربة السودانية، والاماراتية، والماليزية، والهندية، والأمريكية، والأوربية، وغيرها، وفي ضوء تلك التجارب، تم إعداد الضوابط والقواعد العامة للتعليم عن بعد.

واستتادا إلى مخرجات تلك التجارب، وورش العمل، وبعد استقراء الضوابط العربية والعالمية للتعليم الإكتروني، صدر القرار الوزاري رقم 170 لسنة 2007م، ويسمى: (نظام الضوابط العامة للتعليم المفتوح والتعليم عن بعد)، ويقتصر هذا النظام على التخصصات الإنسانية فقط، ويُمنع في التخصصات التطبيقية التي لا يُسمح بها من قبل الوزارة. ومن أبرز الضوابط العامة لهذا النظام، وفقا لمواد وفقرات القرار ، كما ورد في (الجمهورية اليمنية، 2010)، ما يأتي: 1- الحصول على ترخيص خاص للعمل بنظام التعلم عن بعد أو التعليم المفتوح من وزارة التعليم العالي شريطة أن تكون الجامعة قد مضى على تأسيسها خمس سنوات على الأقل. 2- توفر لوائح لتظيم العملية التعليمية والإدارية على أن تتضمن رسالة وأهداف هذا النوع من

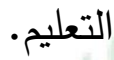
3- توفر الجامعة الميزانية الكافية لضمان حسن سيرة العمل. 4- توفير موقع الكتروني لتسهيل عمليات الاتصال وتقديم الخدمات التعليمية للطلبة. 5- إيجاد البنية التنظيمية: تقوم الجامعة بتوفير بنية تنظيمية وأكاديمية وإدارية. 6- إيجاد البنية التعليمية: تلتزم الجامعة التي تقدم برامج التعليم المفتوح والتعليم عن بعد بالآتي:

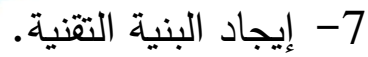

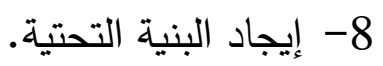


المجلة الدولية لبحوث ودراسات العلوم الإنسانية والاجتماعية (IJSH) المجلد:(الأول) العدد:(الثاني) يناير 2021 د. خليل كحم الخطيب ـ د.نحم ضيف الله الثماري 6، (واقع التعليم الإلكتروني بالجامعات اليمنية).

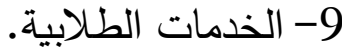

$$
\text { 10- إيجاد ضمان الجودة والتطوير • }
$$

ثم قامت الوزارة بعملية مراجعة شاملة للوضع القائم المتعلق بتقنية الاتصالات والمعلومات (ICT) مجال الإدارة، وفي مجالات التعليم والتعلم، والبحث العلمي، قرّرت الوزارة تقوّية قدرات مؤسسات التعليم العالي، من خلال وضع الخطط الكفيلة بتحسين قدرات التقنية والاتصالات في هذه المؤسسات، وصياغة سياسة وطنية لتقنية معلومات التعليم العالي، تبعتها خطة وطنية رئيسية، ثم خطة تنفيذية تم تطويرها بالتعاون مع مستثارين من جامعة دلفت للعلوم والتكنولوجيا في هولندا، وبتمويل المنظمة الهولندية (NUFFIC).(وزارة التعليم العالي، 2006، 32).

وفي ضوء نتائج الدراسات التقييمية لتتنية الاتصالات والمعلومات في التعليم العالي باليمن، ونظرا لأهمية التعليم الاكتروني، صدر قرار رئيس مجلس الوزراء رقم (174) لسنة 2007م، بثأن إنثاء مركز تقنية معلومات التعليم العالي والبحث العلمي، وبالفعل تم تأسيس المركز، وبدأ يمارس أعماله، وله في سبيل تحقيق أهدافه، تتفيذ عددا من المهام والصلاحيات، كان أبرزها كما ورد في (الجمهورية اليمنية، 2010)، ما يأتي:

- اقتراح السياسة العامة لأنظمة وتقنية المعلومات في مجال التعليم العالي والبحث العلمي واقتراح الخطط والبرامج المنفذة لها. - تسهيل ودعم البنية التحتية الضرورية لتقنية المعلومات في كل مؤسسات التعليم العالي في الجمهورية بما يمكن من إيصال الخدمات الإكترونية لهذه المؤسسات. 
المجلة الدولية لبحوث ودراسات العلوم الإنسانية والاجتماعية (ISSH) المجلد:(الأول) العدد:(الثاني) يناير 2021 د. خليل تحمه الخطيب ـ د.محم ضيف الله الثماري 6، (واقع التعليم الإلكتروني بالجامعات اليمنية).

- - المساهمة في بناء الخدمات لتتقية المعلومات كالخدمات المعلوماتية للمكتبات والتعليم الإلكتروني وغيرها في كافة مؤسسات التعليم العالي، بما يتيح لها إمكانية الوصول إلى بنوك البيانات والمعلومات المحلية والعالمية والمساهمة فيها. وفي ذات السياق؛ ومع بداية أحداث ما يسمى بالربيع العبب، تضمنت مخرجات مؤتمر الحوار الوطني في اليمن عام 2011، عددا من التوصيات المتعلقة بالتعليم العالي، وكان من أبرز ما جاء فيها، كما ورد في (وزارة التعليم العالي، 2014، 18- 19)، ما يلي: والاستفادة من التجارب الناجحة المتطورة في هذا الثأن. - - الاهمام بتقديم أنماط جديدة من التعليم؛ كالتعليم الففتوح والتعليم عن بُعد، وبرامج التعليم المستمر ، والدورات القصيرة المدى والطويلة المدى، وأحدث التخصصات التي تتطلبها خطط التتمية وسوق العمل، مع إعادة تأهيل الخريجين لسد متطلبات التنمية وأسواق العمل". وعلى المستوى التنفيذي؛ واستتادا إلى ما تقدم؛ وإلى خبرة أحد الباحثين بنظام التعليم عن بعد، ومعايشته لواقع هذا النظام باليمن منذ نشأته، فقد تم تلخيص هذه التجربة من وجهة نظره كما ورد في (الثماري، 2020)، على النحو الاتي:

1. كانت بداية التعليم عن بعد في اليمن، من خلال جامعة صنعاء، وتحديدا في العام الجامعي 1997- 1998م، بهدف استيعاب وتعليم أولاد المغتربين اليمنيين في الخارج، بتوجيهات رئاسية حينها، وتم التنسيق مع الجالية اليمنية بدولة قطر عام 2000م، ومن ثم في السعودية،

\section{International Journal of Humanities} and Social Sciences Research and Studies (IJHS) The print ISSN is: $2735-5128$ The online ISSN is: $2735-5136$ It is issued by the Excellence Pioneers Academy 
المجلة الدولية لبحوث ودراسات العلوم الإنسانية والاجتماعية (IJSH) المجلد:(الأول) العدد:(الثاني) يناير 2021 د. خليل كمح الخطيب ـ د.نحم ضيف الله الثماري 6، (واقع التعليم الإلكتروني بالجامعات اليمنية).

في مدينتي (جدة، والرياض)، وكانت نيابة شؤون الطلاب في الجامعة هي المشرفة على هذا النظام عبر وحدة مجهزة يديرها نائب رئيس الجامعة لثؤون الطلاب، تحت إثراف رئيس الجامعة، وفي 2007، صدرت توجيهات رئيس الجامعة بالعمل على ضم الوحدة كقسم من أقسام مركز الحاسب الالي بالجامعة.

2.في 2008 صدر قرار رئيس الجامعة بتحويل الوحدة إلى مركز مستقل، يسمى "مركز التعليم عن بعد"، ويهدف إلى تطوير العملية التعليمية في كليات الجامعة من خلال العمل على تحسين أساليب التعليم باستخدام طريقة التعليم الإكتروني في التعليم عن بعد، واتاحة الفرصة للطلاب اليمنيين والمغتربين خارج البلاد لمتابعة دراستهم، وتوظيف شبكة الدعلومات الدولية للاستفادة منها في مضمار التعليم العالي والجامعي، وتصل مدة الدراسة في المركز لأربع سنوات، وينح الخريج بموجبها على شهادة البكالوريوس في كل من كليات العلوم، والحاسوب وتكنولوجيا المعلومات، والاعلام، والتجارة، والآداب، والثريعة. 3. حصلت جامعة صنعاء على أول تصريح رسمي لنظام التعليم عن بعد في عام 2014م، من وزارة التعليم العالي، يليها بعد عام جامعة العلوم والتكنولوجيا، واكتثت بقية الجامعات بالموافقات المبدئية، حتى يتم استيفاء الثروط كاملة. 4. بدأت جامعة العلوم والتكنولوجيا في عام 1999م بالتعليم المفتوح في السعودية، وتوسعت في دول كثيرة حتى بلغ عدد طلبة كلية التعليم المفتوح أكثر من 13 ألف طالب وطالبة، في دول كثيرة، وفي جميع الدحافظات، وبلغت مكاتب الجامعات في جدة والرياض عشرين مكتبا تمثل عشرين جامعة تمارس التعليم بنظام التعلم عن بعد لأولاد المغتربين اليمنيين وغيرهم.

\section{International Journal of Humanities} and Social Sciences Research and Studies (IJHS) The print ISSN is: $2735-5128$ The online ISSN is: $2735-5136$ It is issued by the Excellence Pioneers Academy 
المجلة الدولية لبحوث ودراسات العلوم الإنسانية والاجتماعية (IJSH) المجلد:(الأول) العدد:(الثاني) يناير 2021

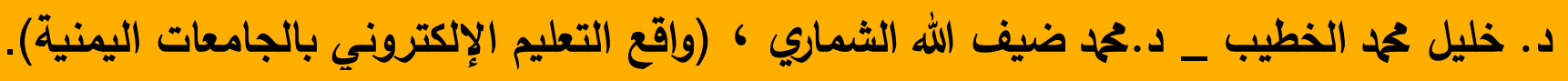

5. قطعت بعض الجامعات اليمنية، شوطا جيدا في إرساء نظام التعليم عن بعد، وتمتلك بنى تحتية جيدة، تلبي متطلبات التعليم عن بعد، والتعليم المفتوح، وهي الجامعات التالية: (صنعاء، عدن، العلوم والتكنولوجيا، المستقبل، الاندلس، العلوم الحديثة، سبأ، الملكة أروى، حضرموت). 6.قامت الوزارة منذ عام 2012م، بمجلس الاعتماد الأكاديمي وضمان جودة التعليم العالي؛ بوضع معايير وأدلة لكل البرامج التعليمية، وفقا للمرجعيات العربية والعالمية، وفرضت على الجامعات الالتزام بها، وتكييف برامج نظام التعليم عن بعد لديها، وفقا لتلك المعايير. 7.اهتمت الوزارة بتعميم وتأسيس البرامج الأكاديمية ذات الطابع التقني، من خلال زيادة عدد الكليات والاقسام، ولم يعد في اليمن أي جامعة، أكانت حكومية، أو خاصة؛ إلا ولديها كلية حاسوب وتكنولوجيا المعلومات.

8. نجحت الوزارة إلى حد مقبول، في ايفاد وابتعاث عدد من الطلبة للالتحاق في برامج الحاسوب، وتكنولوجيا المعلومات، والاتصالات، والتعليم الإكتروني، لدى أعرق الجامعات والأكاديميات والمدارس العالمية، العربية والاجنبية. 9. تنفيذ مشروع تحديث البنى التحتية لنظام التعليم عن بعد، والتعليم الففتوح، وفقا للتطورات الحديثة في مجال التقنية الإلكترونية، ووسائل البث، وإيصال المعلومات، وجعل مخرجات المشروع ضمن المعايير المطلوب توافرها في أي مؤسسة جامعية، ترغب في التدريس بنظام التعليم عن بعد أو التعليم المفتوح، شارك في إنجاز هذا المشروع، مجلس الاعتماد الاكاديمي،

\section{8}

\section{International Journal of Humanities} and Social Sciences Research and Studies (IJHS) The print ISSN is: $2735-5128$ The online ISSN is: $2735-5136$ It is issued by the Excellence Pioneers Academy 
المجلة الدولية لبحوث ودراسات العلوم الإنسانية والاجتماعية (IJSH) المجلد:(الأول) العدد:(الثاني) يناير 2021 د. خليل محمد الخطيب _ د.محمد ضيف الله الشماري ك (واقع التعليم الإكتروني بالجامعات اليمنية).

10. ومركز تقنية معلومات التعليم العالي، والاستعانة بكليتي الحاسوب وتقنية المعلومات، في

$$
\text { كل من جامعتي صنعاء وذمار . }
$$

11. حاولت الوزارة بعمل تجارب لجعل التعليم الإلكتروني مكملا للتعليم النظامي، فقد قامت جامعة 21 سبتمبر بعمل التطبيقات اليومية، والتواصل مع الدكاترة، والساعات المكتبية

$$
\text { إلكترونيا. (الثماري، 2020) }
$$

وفي جامعة حضرموت للعلوم والتكنولوجيا، بدأ نظام التعليم عن بعد فيها عام 2004، لتلبية احتياجات ابناء الدغتربين اليمنيين في السعودية، واعتمد هذا النظام على التعلم الذاتي، أي

$$
\text { اقتصرت الدراسة فيه على الكتاب فقط". (باحشوان، 2007، 2). }
$$

وخلال الفترة 2000- 2012، منحت الوزارة موافقات مبدئية لخمس جامعات يمنية لفتح نظام التعليم عن بعد، وهي: جامعة العلوم والتكنولوجيا، جامعة العلوم الحديثة، جامعة سبأ، بالإضافة إلى جامعتي صنعاء وعدن، وبدأت بعض الجامعات بتأسيس مراكز التعليم عن بعد، ومنحت التراخيص اللازمة، ولكن عندما أدركت الوزارة وجود بعض الاختلالات والمشكلات، والمخالفات القانونية لبعض الجامعات، سرعان ما تم إيقاف العمل بتلك التراخيص عام2013 م، بهذف القيام بمراجعة شاملة لوضع التعليم عن بعد بشكل عام، وفي تلك الجامعات بشكل خاص، وسيتم في ضوء تلك المراجعة الثاملة، وضع الترتيبات اللازمة لـنح تراخيص جديدة للجامعات المؤهلة للقيام بالتعليم عن بعد، والتعليم الدفتوح، وفتح المجال للجامعات المؤهلة لممارسة هذا النوع من التعليم. (الجمهورية اليمنية، 2014، 25). 
المجلة الدولية لبحوث ودراسات العلوم الإنسانية والاجتماعية (IJSH) المجلد:(الأول) العدد:(الثاني) يناير 2021 د. خليل تحمه الخطيب ـ د.يحم ضيف الله الثماري ؛ (واقع التعليم الإلكتروني بالجامعات اليمنية).

وفي سبيل مساعي الوزارة لمكافحة الفساد الأكاديمي والاداري، وتصحيح الاختلالات، وضبط أداء المؤسسات الجامعية، وفقا لتشريعات وقوانين التعليم العالي، ومعايير الجودة والاعتماد الاكاديمي، بغرض ايقاف العبث والفوضى في الجامعات الاهلية والخاصة، اتخذت الوزارة مجموعة من الاجراءات، كان أبرزها، كما ورد في (وزارة التعليم العالي،2016، 24- 43)، ضمن محور تعزيز القدرات المؤسية للوزارة، ما يلي: - حصر كافة برامج التعليم عن بعد ومكاتب التنسيق للجامعات في الداخل والخارج. - ايقاف القبول والتسجيل في اكثر من 186 مكتبا للتنسيق والتعليم المفتوح التابعة للجامعات الاهلية، في الداخل والخارج، لعدم استيفائها الشروط القانونية والعمل على اغلاقها بصورة نهائية، واغلاق 12 جامعة و 4 كليات و40 برنامجا مخالفا. وايقاف القبول والتسجيل في 62 برنامجا مخالفا في الدراسات العليا. - - الاعلان في وسائل الاعلام عن الاغلاق وتحذير الطلاب من الالتحاق بتلك المكاتب. - ايقاف التبول والتسجيل في برامج التعليم عن بعد ومكاتب التتسيق للعام 2015/ 2016 في كافة الجامعات، واتخاذ الاجراءات القانونية ضد الجامعات التي لم تلتزم بالإغلاق. ومع ظهور وباء كورونا، واكتساحه معظم الدول، تم تعليق العملية التعليمية في المدارس والجامعات، بما فيها اليمن، وشعرت قيادة التعليم العالي بصعوبة الموقف، وبدأت الدعوات ترتفع لمراجعة قرارات الوزارة السابقة، والتي قضت بإيقاف التعليم عن بعد. and Social Sciences Research and Studies (IJHS) The print ISSN is: $2735-5128$ The online ISSN is: $2735-5136$ It is issued by the Excellence Pioneers Academy 
المجلة الدولية لبحوث ودراسات العلوم الإنسانية والاجتماعية (IJSH) المجلد:(الأول) العدد:(الثاني) يناير 2021 د. خليل كحم الخطيب _ د.كحم ضيف الله الشماري ، (واقع التعليم الإكتروني بالجامعات اليمنية).

ثم قامت الوزارة بمراجعة تلك القرارات، وأصدرت القرار الوزاري رقم (37) لسنة 2020، بشأن استئناف الدراسة، وعقد الاختبارات للعام الدراسي 2019/ 2020، والترتيب للعام الجامعي القادم 2020/ 2021، وفقا للمشروع المقر من مجلس الوزراء واليته واجراءاته التتفيذية، وكذا العمل بالإجراءات الاحترازية والوسائل المناسبة للوقاية من وباء كورونا (19- COVID)، ومتابعة الاجراءات المعلن عنها من قبل اللجنة العليا لمكافحة الاوبئة، ووزارة الصحة العامة في هذا الجانب. (وزارة التعليم العالي، 2020). تضمن القرار موافقة الوزارة على اختيار الجامعات والكليات بتطبيق النظام التعليمي الذي ، Learning Management System (LMS) سيتم استخدامه لإدارة العملية الاكترونية والتواصل مع الطلاب، وحثت الجامعات على نشر ثقافته بين أعضاء هيئة التدريس والطلاب. وفي هذا اشارة واضحة إلى أن الوزارة قد وجدت نفسها أمام تحدي كبير، مما يتطلب مراجعة وتطوير أنظمة التعليم المعتمدة لديها، ويأتي التعليم الإكتروني في المقدمة، باعتباره اصبح ضرورة وليس ترفا، وخاصة في زمن المخاطر والاوبئة والكوارث، واثناء الازمات، إلا أنه سيظل تحديا كبيرا، ويتطلب مزيدا من الإعداد والتخطيط والتطوير ، والكثير من الجهد والوقت والمال. وفي ضوء ما تقدم؛ تتلخص الجهود المبذولة لوزارة التعليم العالي والبحث العلمي بالجمهورية اليمنية تجاه التعليم الالكتروني، في تضمين هذا النوع من التعليم في الخطة الاستراتيجية الوطنية 2006- 2010، وسن التشريعات والضوابط والقواعد العامة للتعليم عن بعد والتعليم الفنتوح عام 2007، والدعوة لنشر ثقافة التعليم الإكتروني بين الجامعات، واقامة العديد من الورش والندوات التعريفية، وتأسيس مركز تقنية المعلومات 2007، ومنح تراخيص رسمية لبعض الجامعات، 
المجلة الدولية لبحوث ودراسات العلوم الإنسانية والاجتماعية (IJSH) المجلد:(الأول) العدد:(الثاني) يناير 2021 د. خليل محم الخطيب ـ د.حمح ضيف الله الشماري ، (واقع التعليم الإلكتروني بالجامعات اليمنية).

وتراخيص مؤقتة للبعض الاخر ، ومع ظهور وباء كورونا المستجد كوفيد 19، أصدرت الوزارة قرارا وزاريا، والية تتفيذية، تتضمن موافقة الوزارة على اختيار الجامعات والكليات النظام التعليمي الذي سيتم استخدامه لإدارة العملية الآكترونية في التعليم الجامعي. ودعت الوزارة الجامعات إلى تعزيز القدرات المؤسسية لها، وتطوير البنى التحتية في مجال الاتصالات وتقنية المعلومات، والاستفادة من التكنولوجيا الحديثة، وتدريب الأساتذة والطلبة على المداخل الجديدة في التعليم الرقمي، ومنها التعليم الإكتروني، وخاصة في زمن المخاطر والأزمات والاوبئة. إجابة السؤال الثاني:

ما واقع نظام التعليم الإكتروني بالجامعات اليمنية؟ وما أبرز التحديات التي تواجهه؟ لمعرفة واقع التعليم الإككتروني لاى الجامعات اليمنية، وكثف التحديات والمعوقات التي تواجهه، تم استقراء الادبيات، والتقارير ، واستخلاص التجارب اليمنية السابقة، وتوصل البحث إلى جملة من النتائج المرتبطة بالواقع والتحديات معا، يمكن إيجازها كالاتي: 1- المركزية الثديدة وتقادم الهياكل التنظيمية:

كثفت دراسة (أبو غانم، 2013)، عن وجود عدد من المعوقات الادارية لتطبيق الادارة الاككترونية، تتمثل أبرزها في المركزية الثديدة لدى القيادات الادارية، وتقادم الهياكل التظظيمية، وعدم توافقها مع تطبيقات الادارة الاككترونية، وضعف التتسيق بين الوحدات الادارية، بالإضافة إلى قلة الفرص المتاحة للإداريين، لحضور الندوات والمؤتمرات المتعلقة بالإدارة الالكترونية.

\section{International Journal of Humanities} and Social Sciences Research and Studies (IJHS) The print ISSN is: $2735-5128$ The online ISSN is: $2735-5136$ It is issued by the Excellence Pioneers Academy 
المجلة الدولية لبحوث ودراسات العلوم الإنسانية والاجتماعية (IJSH) المجلد:(الأول) العدد:(الثاني) يناير 2021 د. خليل تحمه الخطيب ـ د.بحمد ضيف الله الثماري ؛ (واقع التعليم الإلكتروني بالجامعات اليمنية).

\section{2- غياب الرؤية المستقبلية لاى السلطة وضعف الوعي المجتمعي:}

كثفت دراسة (الرميمة، 2009)، عن قلة الاهتمام من قبل الدولة بهذا النظام وذلك نتيجة عدم وضوح الرؤيا عند بعض المسؤولين القائمين على العملية التعليمية بأهمية نظام التعليم عن بعد، اضافة إلى وجود نظرة سلبية لنظام التعليم عن بعد من قبل المسؤولين عن السياسة التعليمية، والجامعات، والمجتمع نفسه، وهذا يعود إلى قلة استخدام التكنولوجيا الحديثة. 3- ضعف الاهتمام بالإدارة الاكترونية لاى القيادات:

خلصت الدراسات المحلية المتعلقة بالإدارة الالكترونية في التعليم الجامعي باليمن، إلى أن الادارة الجامعية لا تزال تمارس الأساليب التقليدية، في معظم اعمالها الادارية والمالية، ولم تستكمل البنية التقنية في الجامعات، ويختلف واقع الادارة الاكترونية من جامعة لأخرى بنسب متفاوتة. وفي هذا الجانب؛ كثفت دراسة (الدعيس، 2014)، عن غياب الرؤية والخطط لتبني الإدارة الالكترونية، والاعتماد على الأسلوب البيروقراطي المركزي الذي لا يتناسب مع تطبيق الإدارة الالكترونية، وقلة امتلاك القيادات الأكاديمية لمهارات الإدارة الالكترونية. 4 - عدم الثبات في السياسات والخطط المتبعة: ساهمت الصراعات والاضطرابات المتلاحقة التي شهدتها اليمن، في عدم ثبات السياسات، والخطط المرسومة، لترسيخ نظام التعليم الإلكتروني في الجامعات والكليات اليمنية، وتعد هذه المشكلة من أكبر المشكلات، حيث يتم نسف ما سبق من جهود، والعودة من نقطة الصفر ، مما يتسبب في إهدار الطاقات والموارد، وعدم الاستفادة من نسبة الانجازات المحققة سلفا، وتأخير

International Journal of Humanities and Social Sciences Research and Studies (IJHS) The print ISSN is: $2735-5128$ The online ISSN is: $2735-5136$ It is issued by the Excellence Pioneers Academy 
المجلة الدولية لبحوث ودراسات العلوم الإنسانية والاجتماعية (IJSH) المجلد:(الأول) العدد:(الثاني) يناير 2021 د. خليل محمد الخطيب ــ د.محم ضيف الله الشماري 6 (واقع التعليم الإكتروني بالجامعات اليمنية).

عملية التحول الرقمي في التعليم الجامعي. كما ينبغي الحفاظ على التجارب الناجحة، ومعالجة جوانب القصور ، وتطويرها، والبناء عليها، ومحاكاتها من قبل الاخرين. 5 - 5 - 5ف البنى التقنية الاساسية:

كثفت دراسة (معزب، 2008)، عن عدم وجود بنية أساسية لمستحدثات تكنولوجيا التعليم بالجامعات اليمنية، وضعف المعرفة بها، وقلة المتخصصين في التقنيات، وضعف الإمكانيات المادية، وقصور لاى إدارة الجامعة. وتوصلت الدراسة ايضا إلى أن معرفة أعضاء هيئة التدريس والطلاب بمستحدثات تكنولوجيا التعليم كانت ضعيفة جدا، وان استخدامهم لها ضعيفة جدا، او تكاد تكون منعدمة، مع شحة أغلب عناصر مستحدثات تكنولوجيا التعليم بالكليات، وان المتوفر محدود جدا. وأكدت دراسة (قعشوش، 2011)، أيضا، على ضعف البنيه التحتية، والوسائط التقنية، واقتصار الوسائل التعليمية على المطبوعات، ويتم توزيعها للطلاب عن طريق الاستلام

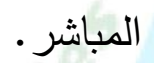
6- ضعف نظم المعلومات والاتصالات الادارية بالجامعات:

تعاني الجامعات اليمنية كغيرها من بقية المؤسسات في اليمن، من أغفال نظم المعلومات، وعدم توفر قواعد بيانات شاملة وحديثة، وغياب الأنظمة الرقمية، وضعف الأتمتة، والارشفة، والتوثيق الالكتروني، وفي مجال نظم المعلومات الإدارية، كثفت دراسة (الدعيس، 2016)، عن وجود برنامجان لدى مركز تقنية معلومات التعليم العالي، وهما: (نظام معلومات شئون الطلاب، ونظام التنسيق الإكتروني)، وبهذا تعد التجربة اليمنية في نظم المعلومات الإدارية تجربة خجولة،

\section{International Journal of Humanities} and Social Sciences Research and Studies (IJHS) The print ISSN is: $2735-5128$ The online ISSN is: $2735-5136$ It is issued by the Excellence Pioneers Academy 
المجلة الدولية لبحوث ودراسات العلوم الإنسانية والاجتماعية (IJSH) المجلد:(الأول) العدد:(الثاني) يناير 2021 د. خليل محما الخطيب ـ د.نحما ضيف الله الشماري ؛ (واقع التعليم الإكتروني بالجامعات اليمنية).

ابسبب ضعف البنية التقنية، وعدم تفاعل القيادات الجامعية، ومدراء نظم المعلومات الإدارية في الجامعات، مع برامج نظم المعلومات المعدة خارجها. أما الاتصالات الادارية، فكثفت دراسة (سالم، 2014)، عن جملة من النتائج، أبرزها: ضعف الاتصالات الادارية، مما يتطلب خمس سنوات للانتقال إلى تطبيق نظم وبرامج الاتصالات الإدارية الآكترونية بالجامعة.

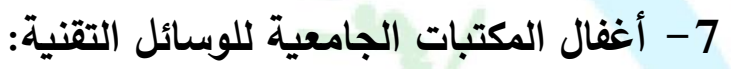

كثفت دراسة (الحباري، 2015)، عن وجود قصور واضح في استخدام واستثمار تكنولوجيا المعومات في الدكتبات الجامعية، مثل: (البريد الإكتروني، موقع الإنترنت، خدمة الويب .الخ)، كما تستخدم المكتبات الجامعة الأهلية 15 نوعاً من وسائط تخزين المعلومات واسترجاعها، بينما تستخدم المكتبات الحكومية 11 نوعاً من الوسائط. 8- ضعف البرامج التدريبية في مجال التعليم الاكتروني: يظل التدريب رديف التعليم، وفي الجامعات اليمنية تقل فرص التدريب والتعلم المستمر، سواء للاكاديميين، أو للإداريين، وفي مجال التعليم الآكتروني، خلصت (المطري، 2011)، إلى أن نسبة من اخذوا دورات في الحاسب الالي في الجامعات اليمنية (70\%)، ونسبة من اخذوا دورات في التعلم الإكتروني (17\%)، ونسبة من اخذوا دورات في مهارات التعلم الإكتروني (38\%). 
المجلة الدولية لبحوث ودراسات العلوم الإنسانية والاجتماعية (IJSH) المجلد:(الأول) العدد:(الثاني) يناير 2021 د. خليل تحمه الخطيب ـ د.بحمد ضيف الله الثماري ؛ (واقع التعليم الإلكتروني بالجامعات اليمنية).

\section{9-ضعف الجودة واغفال المعايير الدولية:}

على الرغم من وجود ضوابط وقواعد بشأن التعليم عن بعد، صادرة عن وزارة التعليم العالي بقرار وزاري عام 2007، إلا أن نسبة التزام الجامعات اليمنية بها، تختلف من جامعة إلى أخرى، ومن فترة إلى أخرى، ولا توجد رقابة فاعلة لتبع هذا النظام، بهدف تجويد مخرجاته، كما يؤخذ على الجامعات اليمنية، عدم الرجوع إلى المعايير الفنية والتربوية، في تصميم وإعداد برامج ونظم التعليم الاكتروني. (وزارة التخطيط، 2014، 46). ونتيجة لذلك، سارع مجلس الاعتماد الأكاديمي وضمان الجودة في وضع معايير للتعليم المفتوح والتعليم عن بعد، عام 2017، في الوقت الذي كانت الوزارة قد اصدرت قرارا بتوقيف التعليم عن بعد، ولم يتم التأكد من امكانية تطبيق الجامعات لتلك المعايير حتى اليوم. 10 - غياب الخدمات الادارية والتقنية المساندة:

كثفت دراسة (الرميمة، 2009)، عن جملة من المعوقات، كان أبرزها: عدم توفر الاطار البشري، الذي يساعد في تقديم الخدمات الادارية، وتسهيل التواصل بين المعلمين والمتعلمين، وتجهيز كل متطلبات التعليم عن بعد. كما لا توجد برامج الاعداد والتهيئة، ولا اهتمام بالإرشاد الاكاديمي، سواء في التعليم النظامي، ام التعليم عن بعد.

\section{International Journal of Humanities} and Social Sciences Research and Studies (IJHS) The print ISSN is: $2735-5128$ The online ISSN is: $2735-5136$ It is issued by the Excellence Pioneers Academy 
المجلة الدولية لبحوث ودراسات العلوم الإنسانية والاجتماعية (ISSH) المجلد:(الأول) العدد:(الثاني) يناير 2021 د. خليل كحم الخطيب ـ د.نحم ضيف الله الثماري 6 (واقع التعليم الإلكتروني بالجامعات اليمنية).

\section{1- - ندرة القنوات والبرامج التعليمية في اليمن:}

كثفت دراسة (العزعزي، 2010)، عن ضعف مراعاة البرامج التعليمية في مادة الأحياء التي

يبثها التليفزيون اليمني للمعايير التربوية، ويرجع ذلك إلى أسباب عديدة، منها ما يرتبط بالجانب التربوي، ومنها ما يرتبط بالجانب الفني في البرامج، كضعف التصوير والانتاج والاخراج.

$$
\text { 12 - غياب الثراكة مع قطاع الاتصالات والمجتمع: }
$$

لا توجد قنوات اتصال فعالة مع المجتمع وسوق العمل، وفي مجال التعليم الالكتروني، تغيب

الثراكات مع قطاع الاتصالات، وشركات الأنظمة الرقمية، والبرمجيات، ولا يستفاد منها في تطوير البنية التقنية بالجامعات، وكذا في تحسين خدمات الانترنت، واعداد المحتوى التعليمي، وفقا لمتطلبات التعليم الالكتروني. 13- ضعف القدرات والمهارات التقنية لاى الأساتذة والاداريين: يعاني كثير من اساتذة الجامعات اليمنية من الامية التكنولوجية، وخاصة في مجال التعليم الرقمي، نظرا لأن الأساليب التعليمية الرسمية لا تزال تقليدية، ولا تتوفر فرص النمو المهني، والتدريب والتعلم المستمر في المجال التقني، إلا ما كان على نفقة الاستاذ الجامعي نفسه، في معظم الجامعات. وفي هذا السياق؛ اشارت (وزارة التخطيط، 2014، 33)، إلى ضعف قدرات كثير من الهيئة التدريسية والإدارية، في التعامل مع التقنية، والأجهزة، والثبكات الحاسوبية. 
المجلة الدولية لبحوث ودراسات العلوم الإنسانية والاجتماعية (IJSH) المجلد:(الأول) العدد:(الثاني) يناير 2021 د. خليل تحمه الخطيب ـ د.بحمد ضيف الله الثماري ؛ (واقع التعليم الإلكتروني بالجامعات اليمنية).

وعلى الرغم من هذه التحديات، يشير أحد الخبراء المحليين، ومستثاري التعليم العالي في

اليمن، إلى أهمية تطوير نظام التعليم الاككتروني، خاصة " وكان لاى بعض الجامعات اليمنية بنى إلكترونية حديثة، وأنظمة وبرامج جيدة، ولولا الحصار المفروض على اليمن منذ خمس سنوات؛ لكان الحال افضل مما هو عليه الان. كما خلفت الحرب دمارا واسعا، واثارا كبيرة، فقد تضررت خطوط الإنترنت، نتيجة القصف والحصار وعدم الصيانة، وأصبحت سرعة الإنترنت محدودة، ورغم ذلك؛ عملت الوزارة مع الجامعات على التعامل مع التعليم الإكتروني وفقا للبنى التحتية الموجودة، وهي جيدة ووفقا لسرعة الإنترنت المحدودة. (الثماري، 2020). كما أن مسالة التحديث، باتت ضرورية، ولكن بطريقة مدروسة، وبشكل تدريجي، "مما يتطلب إعداد خطة خمسية للتحول الرقمي في مجال التعليم العالي، وتوفير المتطلبات اللازمة، تحت اشراف وزارة التعليم العالي والبحث العلمي". (Al-Baadani, 2020 (A).

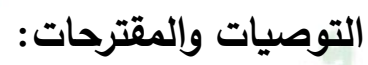

باستقراء نتائج الدراسة، خلص البحث إلى جملة من التوصيات والمقترحات، قد تفيد صناع القرار والسياسات التعليمية، والقيادات الجامعية، والمجتمع، في تطوير/ نظام التعليم الاكتروني، واعتماده نظاما اساسيا وفاعلا لدى الجامعات اليمنية، لمواجهة المخاطر والاوبئة، حاضرا ومستقبلا، ومن تلك التوصيات والمقترحات، ما يأتي: - التدرج في عملية التحول الرقمي في التعليم الجامعي في ضوء خطة خمسية يشترك في اعدادها كافة المستفيدين، وتشرف عليها وزارة التعليم العالي والبحث العلمي. 
المجلة الدولية لبحوث ودراسات العلوم الإنسانية والاجتماعية (IJSH) المجلد:(الأول) العدد:(الثاني) يناير 2021 د. خليل تحمه الخطيب ـ د.تحمد ضيف الله الثماري ؛ (واقع التعليم الإلكتروني بالجامعات اليمنية).

- مراجعة وتطوير السياسات والضوابط المحلية لنظام التعليم الإكتروني وفقا للمعايير العربية والدولية بواسطة مجلس الاعتماد الأكاديمي وضمان الجودة. - إعادة هندسة الهياكل والعمليات والاجراءات للإدارة الجامعية، واتباع أساليب الادارة الاككترونية، بما يتناسب مع متطلبات تطبيق نظام التعليم الإكتروني. - - نشر ثقافة التحول الرقمي وتهيئة الجامعات والطلبة والمجتمع للتعامل مع التعليم الإكتروني

$$
\text { كضرورة وقت الازمات والاوبئة. }
$$

- - تعزيز القدرة المؤسسية للجامعات اليمنية بصورة عامة، والبنية التقنية بوجه خاص.

- الاهتمام بالعنصر البشري لإدارة التعليم الالكتروني، من خلال التعليم والإعداد المسبق، والتدريب أثناء الخدمة، إذ يحتاج التعليم الاكتروني، كوادر بشرية مؤهلة تأهيلا خاصا، من حيث امتلاك الثقافة التقنية، وإجادة التعامل مع الأجهزة الإلكترونية الخاصة بالتعليم عن بعد، والتعليم المفتوح، من حواسيب، وسبورات إكترونية، وأجهزة القاعات الافتراضية، والاستديوهات، وأجهزة البث الفضائي، وإعداد البرامج التعليمية، والمحتوى المعرفي، بما يتتاسب مع هذا النظام. - إيلاء المواقع الاكترونية والمستودعات الرقمية ونظم المعلومات أهمية بالغة. - حماية مؤسسات التعليم العالي، والحفاظ على العقول الأكاديمية من الهجرة، ومن مخاطر الصراع، والاوبئة، وتوفير متطلباتهم، وحقوقهم المادية والمعنوية. - - تعزيز التعاون مع المؤسسات الجامعية المماثلة عربيا ودوليا، والاستفادة من الخبرات الناجحة، ومنها تجربة جامعة القدس المفتوحة.

International Journal of Humanities and Social Sciences Research and Studies (IJHS) The print ISSN is: $2735-5128$ The online ISSN is: $2735-5136$ It is issued by the Excellence Pioneers Academy 
المجلة الدولية لبحوث ودراسات العلوم الإنسانية والاجتماعية (ISSH) المجلد:(الأول) العدد:(الثاني) يناير 2021 د. خليل تحمه الخطيب ـ د.نحمد ضيف الله الثماري ؛ (واقع التعليم الإكتروني بالجامعات اليمنية).

- تتمية المسؤلية الاجتماعية لدى القطاع الخاص وشركات التقنية والأنظمة الرقمية والاتصالات ومزودي خدمة الانترنت لمساندة الجامعات على التحول الرقمي. - استيعاب حملة التعليم عن بعد في سوق العمل والقطاعين الحكومي والخاص. - مساندة التعليم العالي من قبل المؤسسات الاعلامية لإيجاد ثثافة ومعرفة إلكترونية قادرة على

$$
\text { التعامل مع التطورات الراهنة. }
$$

- إجراء دراسات تقويمية لنظام التعليم الإكتروني وتحديد معوقاته ومتطلبات تطويره باستمرار .

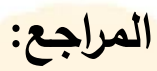

1. ابو غانم ، هناء مجاهد احمد.(2013). تصور مقترح لتطبيق الادارة الاكترونية في كليات التربية بالجامعات الحكومية الينية، ماجستير، ذمار ، اليمن.

2. باحشوان ، عبدالله عيظة.(2007). مستقبل التعليم عن بعد في جامعة حضرموت للعلوم والتكنولوجيا، ورشة التعليم الإكتروني عن بعد 2007، جامعة صنعاء، اليمن.

3. الجرادي ، خالا محسن ثابت.(2005). رؤية مستقبلية لإنثاء جامعة مفتوحة في الجمهورية اليمنية، دكتوراه، أصول تربية، جامعة عين شمس، القاهرة، مصر . 4. الجمهورية اليمنية. (2015). مؤشرات التعليم في الجمهورية اليمنية، مراحله - أنواعه المختلفة، رئاسة الوزراء، المجلس الاعلى لتخطيط التعليه، الامانة العامة، صنعاء، اليمن.

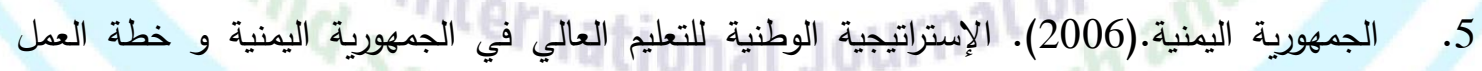

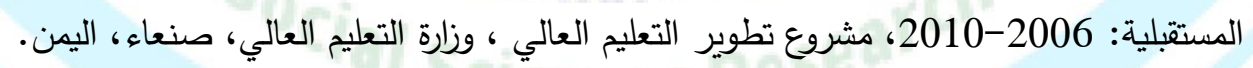

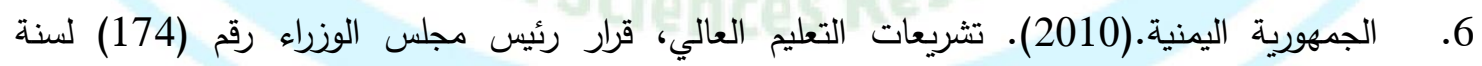

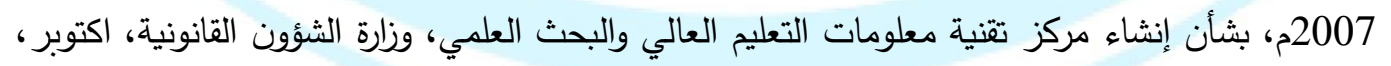
2010،صنعاء، اليمن.

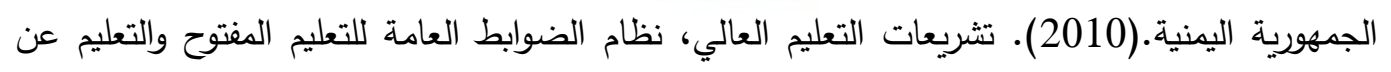
بعد، القرار الوزاري رقم (170)، لسنة 2007م، وزارة الثؤون القانونية، اكتوبر، 2010، صنعاء، اليمن. International Journal of Humanities and Social Sciences Research and Studies (IJHS) The print ISSN is: $2735-5128$ The online ISSN is: $2735-5136$ It is issued by the Excellence Pioneers Academy 
المجلة الدولية لبحوث ودراسات العلوم الإنسانية والاجتماعية (ISSH) المجلد:(الأول) العدد:(الثاني) يناير 2021 د. خليل تحمل الخطيب ـ ـ.ـحما ضيف الله الثماري 6 (واقع التعليم الإكتروني بالجامعات اليمنية).

8. الجمهورية اليمنية.(2020) تجديد اتفاقية تفاهم بين وزارة التعليم العالي والبحث العلمي والمركز المركز الوطني للمعلومات، مركز تقنية معلومات التعليم العالي، صنعاء، اليمن.

9. الحباري ، سمر جمال أحمد.(2015). استخدام تكنولوجيا المعلومات في المكتبات الجامعية اليمنية الحكومية والأهلية، ماجستير ، جامعة صنعاء، اليمن. 10. حيدر ، عبد اللطيف حسين.(2015). إعادة هيكلة التعليم العالي - من تعليم عال إلى تعلم عال.

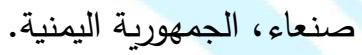

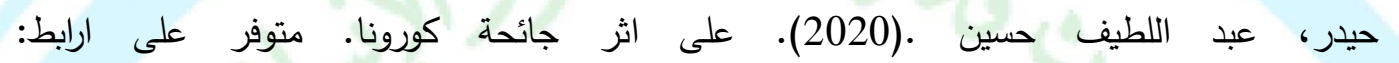
.11 file://C:/Users/AT/Desktop/\%D8\%A8\%D9\%84\%D9\%88\%D8\%AA\%D9\%88\%D /13 8\%AB/bluetooth_content_share\%20\%E2\%80\%AB\%E2\%80\%AC.html $.2020 / 4$ الحيفي ، عبدالله محمد هاشم.(2009). معوقات استخدام أعضاء هيئة التدريس في كليتي العلوم و التربية ،جامعة صنعاء للتقنيات التعليمية الرقمية. ماجستير ، جامعة صنعاء، اليمن. الدعيس ، أماني عبد الواسع خالد ناجي.(2014). برنامج تدريبي مقترح لتطوير المهارات الإدارية لدى القيادات الأكاديمية بجامعة تعز في ضوء متطلبات الإدارة الالكترونية. ماجستير ، تعز ، اليمن. الدعيس ، عبدالكريم سعيد عبده قاسم.(2016). تطوير نظم المعلومات الإدارية في الجامعات اليمنية، دكتوراه، ادارة وتخطيط تربوي، التربية، صنعاء، اليمن. الدهان ، جمال علي خليل.(2020). أزمة التعليم والتعلم في ظل كورونا: الأفق والتحديات، متوفر على .15 https://www.new-

educ.com/\%d8\%a7\%d9\%84\%d8\%aa\%d8\%b9\%d9\%84\%d9\%8a\%d9\%85\%d9\%88\%d8\%a7\%d9\%84\%d8\%aa\%d8\%b9\%d9\%84\%d9\%85\%d9\%81\%d9\%8a-\%d8\%b8\%d9\%84. 2020 /5 / بتاريخ 4d9\%83\%d9\%88\%d8\%b1\%d9\%88\%d9\%86\%d8\%a7, 16. الرميمة ، عفيف عبدالله.(2009). التعليم الجامعي عن بعد وافاقه المستقبلية في الجمهورية اليمنية :جامعه العلوم والتكنولوجيا نموذجاً، دكتوراه، تونس، تونس. 17. سالم ، فضل راجح عبد القوي.(2014) • تصور مقترح لتطوير الاتصالات الإدارية الاككترونية في جامعة عدن، جامعة عدن، اليمن. 18. السباعي ، زهير أحمد. (2020). كورونا الجديد 19 - Covid، ط 1، مركز الادب العربي للنشر والتوزيع، السعودية. and Social Sciences Research and Studies (IJHS) The print ISSN is: $2735-5128$ The online ISSN is: $2735-5136$ It is issued by the Excellence Pioneers Academy 
المجلة الدولية لبحوث ودراسات العلوم الإنسانية والاجتماعية (IJSH) المجلد:(الأول) العدد:(الثاني) يناير 2021 د. خليل محمد الخطيب ـ د.محم ضيف الله الشماري ك (واقع التعليم الإلكتروني بالجامعات اليمنية).

19.الشماري ، ححمد ضيف الله.(2020). التعليم عن بعد في اليمن، مقابلة شخصية، مكتب مستشار وزارة

$$
\text { التعليم العالي والبحث العلمي، صنعاء، اليمن. }
$$

20. صالح ، إبراهيم عبدالله حسين.(2012). واقع استخدام التعليم الإلكتروني في كلية التربية والألسن جامعة

$$
\text { عمران بالجمهورية اليمنية(دراسة مسحية)، ماجستير ، القاهرة، مصر . }
$$

عبد الرزاق ، فؤاد. (2020). دور مركز تقنية معلومات التعليم العالي في مواجهة جائحة كورونا، مقابلة

$$
\text { شخصية، مركز تقنية المعلومات، صنعاء، اليمن. }
$$

العزعزي ، اروى احمد عبدالله.(2010). تقويم البرامج التعليمية في تلفزيون الجمهورية اليمنية في ضوء

$$
\text { المعايير التقانية والتربوية. ماجستير، القاهرة، مصر . }
$$

العليمي ، ماجد عبدالحميد محمد. (2005 ). تظوير نظام لإدارة التعليم الجامعي المبني على الانترنت،

$$
\text { ماجستيرن جامعة الجزية، السودان. }
$$

فراج ، أسامة محمود. (2014). التعليم والتعلم المستمر وقضايا الالفية الثالثة. أكاديمي للنشر والخدمات

العلمية، معهد الدراسات التربوية، جامعة القاهرة، مصر .

الفقي ، سها عوض تحمد.(2010). تطبيق معايير الجودة والاعتماد الأكاديمي بنظام التعليم الجامعي

المفتوح في مصر - الخبرة البريطانية. مؤتمر علمي بعنوان: معايير الجودة والاعتماد في التعليم المفتوح في مصر والوطن العربي، 27- 28 مارس 2010، كلية التربية، جامعة بور سعيد ، مصر، المجلد

$$
\text { الثاني، ص ص: 625- 692. }
$$

قعشوش ، علي علي حمح ناصر.(2011). واقع التعليم عن بعد في الجامعات والمعاهد العليا اليمنية

ومدى تطبيقه في تدريس مادة الرياضيات، دكتوراه، أم ردمان الاسلامية، السودان.

المطري ، ابراهيم ناجي صالح.(2011). دراسة تقويميه للتعليم الإكتروني في الجامعات اليمنية في ضوء

$$
\text { الاتجاهات العالمية المعاصرة، ماجستير ، اسيوط، مصر . }
$$

28. مطهر ، محمد محم. (2007). الضوابط العامة للتعليم المفتوح والتعليم عن بعد. ورشة التعليم الإكتروني عن

بعد، 2007، جامعة صنعاء، اليمن.

29. معزب ، مححد على مصلح. (2008). دراسة تقويمية لاستخدام مستحدثات تكنولوجيا التعليم بكليات التربية

في الجامعات الحكومية اليمنية وخطة مقترحة لتطوير استخداماتها. ماجستير، معهد البحوث العربية،

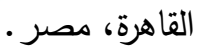

30. وزارة التخطيط.(2014). محور التعليم العالي والبحث العلمي، مشروع الرؤية المتكاملة للتعليم في اليمن،

وزارة التخطيط والتعاون الدولي. صنعاء، اليمن.

وزارة التعليم العالي. (2016). تقرير الانجاز السنوي 2016، وزارة التعليم العالي، صنعاء، اليمن.

\section{International Journal of Humanities} and Social Sciences Research and Studies (IJHS) The print ISSN is: $2735-5128$ The online ISSN is: $2735-5136$ It is issued by the Excellence Pioneers Academy 
المجلة الدولية لبحوث ودراسات العلوم الإنسانية والاجتماعية (ISSH) المجلد:(الأول) العدد:(الثاني) يناير 2021 د. خليل محمد الغطيب _ د.محمد ضيف الله الشماري ؛ (واقع التعليم الإكتروني بالجامعات اليمنية).

32. وزارة التعليم العالي.(2014). دليل التعليم العالي، 2014/ 2015، وزارة التعليم العالي والبحث العلمي، صنعاء، اليمن.

33.وزارة التعليم العالي.(2020). القرار الوزاري رقم (37) لسنة 2020، بشأن استئناف الدراسة، وعقد

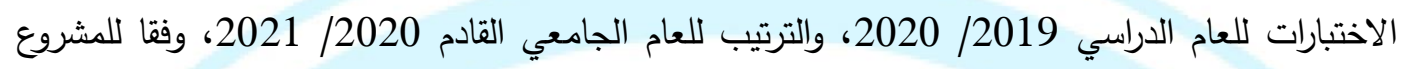

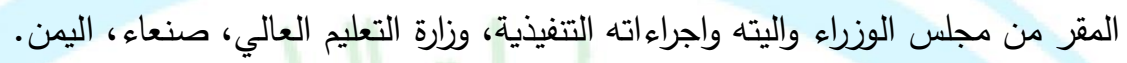

34. Al-Baadani, Ahmed Abdulkarem \& Abbas, Mohammed.(2020). The Impact of Coronavirus (Covid- 19) pandemic on Higher Education Institutions (HEIs) in Yemen: Challenges and Recommendations for the Future. European journal of Education Studies, Vol. 7, Issue. 7, 2020, pp: 68 - 82. 


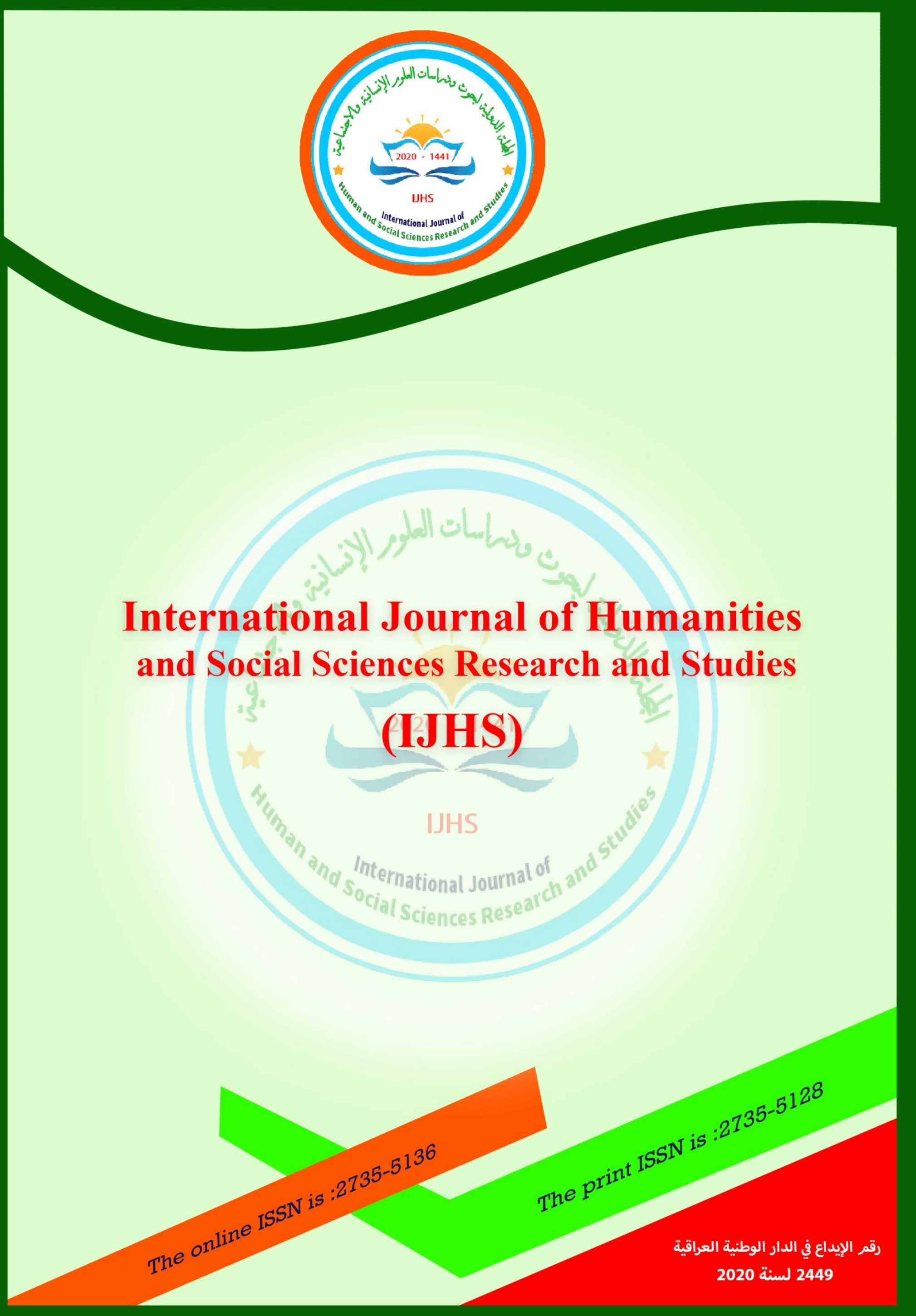

